\title{
Cognitive History and Cultural Epidemiology
}

Christophe Heintz

Abstract

Cultural epidemiology is a theoretical framework that enables historical studies to be informed by cognitive science. It incorporates insights from evolutionary psychology (viz. cultural evolution is constrained by universal properties of the human cognitive apparatus that result from biological evolution) and from Darwinian models of cultural evolution (viz. population thinking: cultural phenomena are distributions of resembling items among a community and its habitat). Its research program includes the study of the multiple cognitive mechanisms that cause the distribution, on a cultural scale, of representations and material cultural items. By a detailed analysis of the social cognitive causal chain that occurred in the past, one can find out - and specify - which are the factors of attraction that account for cultural stability as well as historical cultural change.

After reviewing recent research and developments in cognitive history, I present the concept of cultural attractor and explain why cultural attractors are historically variable. In doing so, I emphasize the role of historically constituted cognitive mechanisms, which account for much of historical cultural developments. I argue that the framework of cultural epidemiology can better account for these important historical phenomena than either evolutionary psychology accounts of culture or dual inheritance theory. I conclude that describing and explaining the history of cultural attractors is a good research goal for historians.

\section{Cognitive History and Cultural Change}




\section{Rationale for cognitive history: the cognitive makeup of history}

Historians are brought to hypothesize on the mental states of the agents whohave lived and acted in the period they study. Describing the intentions, desires, motives, feelings and thought of past agents is fully part of the historians' agenda. In particular, explaining past behaviors implies specifying the mental states that generated these behaviors. Thus, historians propose explanations that draw on psychological concepts and lead to psychologicaltheorizing about agents' thoughts and intentions. Cognitive history is research done with the assumption that psychology and cognitive science provide useful tools and theories for historiography. There are several reasons for thinking that studies in cognitive history will foster better understanding of the past, which I will spell out in the rest of this chapter.

The relevance of psychology to the social sciences has been emphasized in the last two decades, most notably by Tooby \& Cosmides (1992) and Sperber(1996). Although their main target was social and cultural anthropology, their arguments also apply to historiography. Cosmides and Tooby denounce the social scientists' assumption that humans are born with a mind like a blank slate, upon which culture can write. They argue, with evidence from psychology, that the inferential devices implemented in brains are contentloaded and constrain behavior and culture in significant ways. Sperber specifies the way in which psychological properties affect social and cultural phenomena. Cognitive processes, Sperber (2006) explains, are comprised of causal chains where the output of a process constitutes the in-put of another process; they form Cognitive Causal Chains (CCCs). Many events of these causal chains happen within the brain (perception, memory, mental inferences and motor control), but some other relevant events involve elements "outside of the skull" (this is the main claim of scientists of embodied, situated and distributed cognition; see: Clark 1997; Hutchins 1995). In particular, cognitive processes can involve social interactions: Chains of cognitive processes can extend across individuals and have a social character. In the simplest 
cases, the behavioral output of some individual's CCC may serve as a perceptual inputfor other individuals' CCCs and link them in a single Social CCC or SCCC for short (Sperber, 2006).

Sperber gives the simple example of someone ordering a pizza, where information is passed on from the client to the person taking the phone call, to the cook, and then to the deliverer. At each step information is transmitted and processed, and actions are taken. Historical events are also composed of such social cognitive causal chains. Take a chain of events leading to the Massacre of Saint Barthelemy in 1572 in France: the Guise family forms the intention of assassinating the Huguenot Colligny, the action is planned, the instructions are given to the would-be assassin, but the attempt fails. The Huguenots want the culprits to be found and punished. In order to preempt possible retaliation from the Huguenots, Catherine de Medicis organizes, together with her son the King of France, the assassination of the main Huguenot leaders staying in Paris. Orders are given to the municipalauthorities and to the King's Swiss Guard; catholic citizens are armed against possible uprising of the Huguenots. Following the first murders, the people of Paris, of strong Catholic conviction, murdered some 2000 Huguenots staying in Paris. The violence then spread throughout France. This chain of events is causal by the production, transmission and transformation of representations. The chain is cognitive because it is best explained by invoking semantic relations between what agents thought, perceived and communicated. Thus, the mental representations of the members of the Guise family had an effect, through a causal chain unknown to historians, on the would-be assassin. The attempted assassination informed the Huguenots of others' intentions and power to harm them; they had interests in asserting their rights to justice. Catherine de Medicis construed a mental representation of the intentions she attributed to the Huguenots ('Huguenots want to retaliate'). She anticipated their possible actions. She communicated her solution for avoiding what she thought may be a danger (Huguenots' 
retaliation). The emphasized terms are semantic descriptions of some events, and their relations are themselves expressed in terms of production and flow of representations; mental representations are causes of the actions of people having them, and public representations cause the production of mental representations, as in communication for instance where sounds cause the listener to reconstruct what the speaker means

Historians attempt to reconstruct social cognitive causal chains by using simple assumptions drawn from naive psychology. In general, this reconstruction is done by using simple assumptions of the kind: people have beliefs, desires and interests, and these account for their decisions and behavior. In fact, the above historical account is controversial: we do not know for certain who first commanded the assassination of Coligny, and we do not know for certain the origin of the plan to murder Huguenot leaders. Was it Catherinede Medicis or rather her son, King Charles XI, who initiated the plan? Was it the result of pressures from the Guise family? Was it directly planned by the brother of the king and Henri de Guise, who were in search of authority and power? In order to tell apart the numerous possible chains on the basis of limited evidence, the historiographer needs to be generous in psychological assumptions. In the end, it is not only the historical data that determinehistorical theories, but also the psychological intuitions of the historians, who try to understand the characters they study, their beliefs, goals and interests. Historians use their naive psychological abilities to provide informative historiography. Couldn't historiography benefit from input from scientific psychology and cognitive science?

\section{Current Developments in Cognitive History}

\section{Cognitive history of science and technology}

The need for cognitive history has been felt in the history of science and technology, where the cognitive processes are non-obvious and historically highly significant. A simplified 
psychology relying only on beliefs and desires as explanatory concepts is largely insufficient for accounting for conceptual innovation. ${ }^{1}$ Nersessian (1995) introduces the methodology and prospects of cognitive history of science as a subfield of cognitive science that studies the thinking practices "through which scientists create, change, and communicate their representations of nature" (p. 194). Cognitive history of science reconstructs historical events that are amenable to cognitive analysis. It already includes analyses of the works of Faraday (Tweney 1985, 1991; Gooding 1990), Maxwell (Nersessian 1984, 1992, 2002), and Bell and Edison (Gorman 1992), as well as studies in the history of natural history (Atran 1990) and the history of mathematics (Netz 1999; Heintz 2007b, chap. 7 and 11). These works attempt to reconstruct scientists' thoughts and activities by using cognitive notions such as "schemata," "mental models," "heuristics," "naive theories," "analogical thinking," "thought experiment," “deductive" and "inductive reasoning", and "procedural knowledge." They analyze through which cognitive processes innovation and conceptual change arise in history. In return, the study of these historical events can contribute to the understanding of cognition because it provides new data on cognition occurring in non-experimental settings. As opposed to researching tasks performed in the psychologists' laboratory, cognitive history of science analyzes how scientific cognition is used in the scientists' own working environments.

Cognitive history of science uses cognitive psychology as source of information for historians about the thought processes available to scientists while scientific cognition is analyzed as it occurred in historical contexts: scientists are socially situated, and this situation accounts in part for their thoughts and behavior. The cognitive historian also attempts to account for the behavior of scientists by generating hypotheses about the actual cognitive processes implemented. The historical case studies furnish empirical data forcognitive

1 The point is not that scientists' desires and interests do not play an important and pervasive role in scientific knowledge formation (see Barnes 1977), but that using only naive psychology in social studies of science leads to a partial picture of the processes of scientific knowledge production. 
theories. There should be, as Nersessian (1995) puts it, a virtuous circle where some assumptions from cognitive science are accorded privileged status in order to get the historical analysis "off the ground," but could further be subject to critical scrutiny. Corrective insights should come from both directions: from cognitive science to cognitive history and the reverse.

\section{Cognitive history of religion}

The question of the usefulness of cognitive science to history has also beenraised in the domain of the history of religion (Whitehouse 2005; Martin 2005). Cognitive science of religion has theorized on the psychological factors that make religious ideas likely to become widespread in time and space. Boyer (2001, chap. 2) and Atran (2002, section 4.7) show that minimally counterintuitive beliefs are more attention-arresting, more easily remembered and more willingly communicated. Religious beliefs are mostly made of such minimally counterintuitive beliefs, and this accounts for their large distribution and recurrence across time and societies. Performing this analysis requires knowledge of cognitive psychology, because whether a given belief is minimally counter-intuitive depends on how intuitive beliefs are produced, and whether their content is constrained by universal features of the human cognitive apparatus. The resulting theory can bring some explanatory powerto the history of religion. For instance, Vial (2005) explains why Luther's theology has been more successful than Zwingli's by pointing out features of Luther's theology that made his claims easier to cognize than Zwingli’s.

Whitehouse's theory of modes of religiosity (2004) also draws on psychology and provides tools for historians. He specifies two distinct ways through which religious beliefs can be memorized: both through memories of things seen and felt (episodic, autobiographic, memory), or through memories of specific content (semantic memory). Thus, religious beliefs can take the form of either episodic or semantic memories, which are distinct cognitivetypes 
of mental representations. The production and transmission of these two types of mental representations require different means: the production and transmission of episodic memories rely on rituals that ensure, through emotional arousal, that the course of events will be remembered as autobiographically salient memories. This is the imagistic mode of religiosity. The production and transmission of semantic memories rely on explicit andrepetitive teaching; it implicates institutionalized learning and deferential behavior towards teachers. This is the doctrinal mode of religiosity. Whitehouse argues that the two modes coexist in any religion but that religions tend towards one or the other. Martin (2005) points out that this cognitive theory of cultural transmission predicts a "divergence of transmissive trajectories over time". The imagistic mode of religiosity implies transmission through emotionally loaded rituals, which create strong feelings of solidarity between those who went through it. The doctrinal mode of religiosity implies institutionalized teaching, and thus a social hierarchy.

\section{Cognitive economic history}

It is likely that cognitive history will soon be applied to other domains, e.g.economic history. There are several factors that could lead to the development of cognitive economic history. First, economists have started to realize that psychology is most useful for understanding and predicting the actual behavior of economic agents, which led to the thriving field of behavioral economics (Gilovich et al. 2002). Second, another developing field of economics is information economics, which studies how information affects economic decisions and the consequent economic performances (the archetypical problem being "information asymmetries," see e.g. Akerlof 1970, and the relevance of the distribution of knowledge is explicated and analyzed by Martens 2004). Information economics emphasizes the economic importance of information, its transformation and distribution among economic agents. Third, the dissatisfaction with neo-classical economics and its unrealistic model of the economic 
agent is felt among economists who want to account for economic changes. Evolutionary economists, in particular, have been searching for alternative models to the neo-classical homo ceconomicus, which is better suited for modeling operations in market than for describing how economies evolve. Evolutionary economists are thus led to use more complex models of economic agents (e.g. Potts 2000, chap. 5) and integrate theories frompsychology (mainly sociobiology and evolutionary psychology) and behavioral economics (e.g. Witt 2003, chap. 8 \& 9).

Douglas North, a major figure in economic history and winner of the Nobel Memorial Prize in Economic Sciences in 1993, incited research in the direction of cognitive economic history. North (2005) argues as follows: in order to understand economic change, one has to account for changes in the institutional infrastructure that importantly determine economic decisions and overall performance. The institutional changes are brought about by economic agents acting on the institutional infrastructures on the basis of their beliefs about what is the case, what should be the case, and how to achieve the intended change. Thus, understanding the process of economic change requires investigating the psychological processes through which agents' intentions emerge. The history of the Soviet Union, briefly reviewed in a chapter of the book, provides a clear account of how beliefs about the world, viz. Marxists beliefs, caused political actions that framed institutions; which led to undesired consequences (e.g. low agricultural production), and several attempts to adjust beliefs, policies, and perceived results. The history of the western world also illustrates the process: "belief structures" such as English people's perception of the rights of the individuals in the $16^{\text {th }}$ century, determined institutional structures such as the Petition of Right of 1628, which in turn changed the environment and later beliefs.

Understanding economic processes seems to call for an analysis of how beliefs evolve, are distributed and processed in the population of economic agents. Historical changes provide 
one of the main sources of empirical data.

\section{Cultural Epidemiology and Cultural Change}

\section{Cognitive cultural history}

Cognitive history has been shown to be useful in the domains of religious and science studies, and it promises to give important insights for economics. Independent of the domain (note that SCCCs can span different domains), the accounts are all about human thought processes in historical context and the factors that constrain the flow and transformation of information.

There are at least two reasons that make a social cognitive causal chain ofinterest for the historian. First, a social cognitive causal chain can be relevant to us because we know it led to some important, desirable or not, consequence. We then want to understand which change in which variables could have led to a different outcome. The chain of events leading to the massacre of Saint Barthelemy, for instance, is highly relevant because we judge that the killings were disastrous. Moreover, the massacre led to a cultural change that has had further historical consequences, including the exodus of the Huguenots' intelligentsia after the revocation of the Edict of Nantes (1685). Cognitive chains that led to less adverse effects are also of interest: for instance, Faraday's reasoning in his laboratory has had important consequences on the future distribution of scientific representations, and on our living conditions.

Second, social cognitive causal chains of the past are of interest to historians to the extent that they are representative causal chains - they often recurred in the past and are informative of the past culture. Here, the scope changes from an important single chain of events, to recurrent chains of less important events. Recurring cognitive causal chains produce cultural phenomena. For instance, studying religious beliefs and practices implies reasoning on relatively large populations where not all actions and thoughts need be tracked down. It is not 
so important, for the historian, whether the blacksmith Jacques Martin living close to the

Bastille went to the mass on the first Sunday of September 1571. What is important, however, is that the population of Paris is mainly composed of strong believers in Catholicism. Most inhabitants of Paris went to the catholic mass in the years that preceded the massacre. It is the large distribution of strong catholic beliefs, as well as beliefs about one's own identity and that of other religious communities (the heretics), which constitute an important phenomenon. This phenomenon is cultural: it is not only constituted by the content of the beliefs (catholicism, beliefs about protestant beliefs) or their relations with singular actions andevents, but also by the distribution of the beliefs in the French population of the 16th century.

In the first and the second case, the cognitive historian questions whichare the cognitive chains that produced the representations that are observed in the historical records (public representations such as letters or reports) or that the historian ascribes to historical agents in order to make sense of their behavior. In the second case, the recurrence also needs to be explained. The question is: What are the principles that account for change and stability of the distribution of representations in the population? The mechanisms thatdistribute representations can involve psychological properties, as when representations are attentionarresting, have inferential potential or are more emotionally provocative. They can also importantly rely on properties of the environment, which can itself be the result of social and historical processes, as when institutions determine who has the authority and means to distribute information (e.g. who can broadcast on the radio). Doing cognitive cultural history ${ }^{2}$

\footnotetext{
${ }^{2}$ This is cultural history that draws on the explanatory power of cognitive science. By 'cultural history' I refer to the historiography of cultural phenomena. However, "cultural history" also refers to a research program, especially in French historiography. It will appear that there are much similarities in the questions and goals of cultural history and cultural epidemiology: cultural history is characterized as "social history of representations" (Ory 2004), which departs from previous history of mentalities because it refuses to use the concept of collective mentalities. Cultural history takes on the project to track down public representations as they were produced and distributed in the period studied, but also which mental representations these public representations generated at the time. For instance, Chartier (1990) insists on the "modes of reading" and the operations through which readers construct the signification of texts. Chartier argues that the reading practices of the 18th century encouraged critical discussion, which was a condition of possibility of the French revolution, because it sapped
} 
implies specifying the factors that led to the advent of cultural phenomena through the description of the recurrent social cognitive causal chains and the constructive cognitive mechanisms that are repeatedly triggered. In particular, the historians explain the evolution of distribution of representation in terms of probabilistic reasoning based on psychological notions (e.g. a representation being memorable or salient). The probabilistic reasoning has itself a causal cognitive underpinning: the cognitive historian specifies a cognitive causal chain that is likely to occur, given what is known of the properties of the human mind and the historical context. Boyer (1998) notes that representations have more or less "cultural fitness [...] understood as the likelihood that a particular representation found at generation $n$ will be found, in some roughly similar version at $n+1$ " (p. 885, my emphasis). One much studied means for a cultural representation to have cultural fitness is totrigger and exploit evolved cognitive abilities. Evolved cognitive abilities constrain cognitive development and lead to universal psychological properties. For instance, the evolved capacity to speak a natural language constrains development so that nearly all adults having grown up in a common social environment speak the same natural language. Likewise, all "normal” adults ascribe beliefs and desires to others thanks to cognitive development of an evolved capacity for what is called naive psychology $y^{3}$. These universal properties of the mind inform the cognitive social scientist about which mental cognitive causal chains are most likely to occur in specified conditions. Boyer talks about "inheritance tracks" when describing how cultural input is likely to be processed by situated agents, given their human evolved abilities.

Cultural epidemiology as a theoretical framework for historians

the monarch of its mystical authority. The proponents of cultural history seem to rejoin cultural epidemiology's view of cultural phenomena as distributions of representations, and they likewise aim at identifying the social cognitive causal chains that distribute cultural representations. 
Sperber (1996) argues that understanding the specifics of mental cognitivecausal chains is as important for the study of culture as the study of pathologies is for medical epidemiology. Cultural phenomena are cultural because they involve recurrence and spread of cultural items, cultural epidemiology aims at studying the reasons for such recurrences and spread, taking into account theories from psychology. Cultural phenomena, Sperber says, can be characterized as distributions of mental representations and public productions in communities and their habitat. For instance, different versions of a tale may be instantiated as mental representations in children and adults' memory, and the versions can be instantiated as public productions in sound wavelength or written inscriptions. A story is cultural to the extent thatits versions are well distributed in space and time. A tale, for example, is being told across several generations and is known by numerous member of a community of the same generation.

Cultural epidemiology provides a good theoretical framework for cognitivecultural history: it allows for a diachronic analysis of cultural phenomena, which are characterized as distributions of representations in time, as well as in space. Cultural representations are made of token representations that remain recognizably similar to past, antecedent, token representations; these token representations must span relatively long periods of time in order to achieve a cultural status. The causes of the existence of cultural representations are also inscribed in time: Sperber points out that the social cognitive causal chains that stabilise representations are "long and lasting" (2001).

Studies in cultural epidemiology (i.e. the work of Atran, Boyer, Hirschfeldand Sperber) have focused on the conditions, and in particular the psychological conditions, for the resilience and continuity in content of some representations. Why and how do representations happen to be successful? Why are some are taken on and spread, while others are rejected,

\footnotetext{
${ }^{5}$ People with autism have limited capacities to develop naive psychology.
} 
radically transformed or simply forgotten? These questions certainly pertain to culturalhistory, but are phrased in terms of causal chains that go through people's cognitive apparatus. Which are these causal processes and mechanisms that distribute representations in a community and its habitat?

What has interested historians most is not only how some beliefs spreadand last, but also how and why beliefs change. Cultural change, however, also falls into the epidemiological rationale: the stability of a cultural representation is always partial and depends on the environmental and culturally contingent conditions that sustain it. Studying how changes in the environmental conditions affect the stability of a representation is indeed a genuine epidemiological question, i.e. one that can fruitfully be answered within this theoretical framework. I will further argue for this claim by showing how historical contingency can be taken into account in the framework of cultural epidemiology. I will emphasize that well-informed (historically and psychologically) descriptions of social cognitive causal chains enable finding out the causes of recurrent production of similar cultural items, and thus the different factors of cultural change and stability. By contrast, the restricted focus of evolutionary psychology on evoked culture and dual inheritance theory on transmitted culture lead these two approaches to culture to neglect the rich interaction between the environment and the cognitive processes that distribute representations and thus produce cultural phenomena.

\section{The Historicity of Cultural Attractors}

One central research goal of social and cultural anthropology is to account for cultural diversity across space, with people from one region having behaviors and beliefs that are relatively similar among themselves, but very different from people from another region. Likewise, cultural history has to provide explanations of cultural diversity across time. In this 
section, I present the notion of cultural attractor as enabling accounts of cultural change and diversity while at the same time taking into account the universal aspects ofhuman psychology.

\section{Beyond the evoked/transmitted culture dichotomy}

It is often assumed that cultural diversity is based on psychological diversity: evolutionary theories of the beginning of the 19th century presupposed differences in the mental abilities of the people of different cultures (e.g. Lévy-Bruhl on pre-logical thinking); and contemporary anthropological relativist theories assume that the mind is so malleable that enculturation accounts for all those psychological properties that ground cultural thinking and behaving. Cultural diversity could be seen as providing an argument againstascribing a role to the universal psychological properties of the mind in framing cultures. If people were bound to think in the same ways, the argument goes, how come they have such different beliefs and types of behaviors across cultures? Cultural epidemiologists and evolutionary psychologists have argued that cultural diversity can be based on properties of the mind that are shared cross-culturally. Their answers, however, differ in ways that I will now explain.

Cosmides \& Tooby (1992, p. 209) argue that even though there is a rich set of universal properties of the mind that strongly constrain cultural production, cultural diversity can arise because the universal mental mechanisms are put to work on different inputs from different environments: people living in the same location are likely to experience similar circumstances, which evoke similar responses, while people living in different locations experience different circumstances that evoke different responses. One obvious example is that people living in hot places tend to be lightly clothed, while people living in cold places wear clothes that keep them from the cold. Thus the variation of environmental conditions provides local similarities and general diversity of responses, thus leading to diverse cultures. Cosmides 
and Tooby call "evoked cultures" the cultural responses to diverse environments, i.e. the local "similarities [in thoughts and behaviors] triggered by local circumstances" (Cosmides \& Tooby, 1992, p. 210). Transmitted culture, by contrast, "is the process whereby the thought and behavior of some individuals (usually from the preceding generation) is passed on to other individuals, thereby causing the present pattern".

Social transmission and environmental evocation are two ways in whichcultural diversity can be brought about. Although Cosmides and Tooby do think evocation and transmission operate together in the production of cultures, their work, and the work of evolutionary psychologists and sociobiologists in general, has largely focused on evoked culture. In order to emphasize the role of evolved cognitive abilities in shaping cultures, they have attempted to explain many cultural phenomena as evoked culture rather than the result of social transmission. The topics investigated in this way include kinship, mating behavior and parental investment - where Hamilton and Trivers' work has provided much insight for evolutionary theorizing (see, e.g., Salmon \& Shackelford 2007).

In order to re-establish the balance, Richerson \& Boyd (2005) emphasize the role of transmitted culture. They provide several cases of cultural phenomena that cannot be accounted for by evocation alone. Technical knowledge, for instance, is cultural knowledge that it is not re-invented by each member of the culture or each generation. Rather, it is transmitted among the members of the culture. It "improves" through Darwinian processes and can become quite complex. Boyd and Richerson have advocated dual-inheritance theory, according to which both genes and cultural variants are transmitted across generations through two different channels. Yet, the evolved cognitive mechanisms that they consider as psychological foundations of culture are mainly enabling cultural transmission (Richerson \& Boyd 2005, chap. 4) and selecting cultural variants (transmission biases: Richerson \& Boyd 2005 p. 69-77). Dual inheritance theorists have given little attention to the cognitive 
mechanisms that construct cultural representations on the basis of input from social interactions. In their models, imitation is mostly a black-boxed cognitive process. It is assumed that the process is such that that the output (imitated behavior) will be sufficiently similar to the input (the model) in sufficiently many cases for the stabilization of cultural items to occur. Evolutionary psychologists and dual-inheritance theorists form two schools of thoughts that emphasize the causal effect of either evolved faculties or social transmission on culture. But in fact, the evoked/transmitted dichotomy is more an artifact of debates between Darwinian theorists of culture than a fruitful way to categorize cultural phenomena. ${ }^{4}$ It results indeed in some misleading oversimplification: by trying to show the importance of the role of either evocation or transmission, one tends to ignore either the constructive processes that involve both what is socially transmitted, which provides input to mental processes, or the properties of the mind, which determine how the input will be processed to produce some further, mental or public, representations. On the one hand, studies of evoked culture emphasize that cultural items are the output of some mental cognitive processes; it tends to ignore that this output contributes to framing the environment in whichneighboring agents,

${ }^{4}$ Atran (2001) states that the divide may originate in "vulgar sociobiology" and the reactions it triggered:

I suspect that Dawkins and colleagues tend to disregard or underplay the role of evolved cognitive architecture in constituting culture for many of the same reasons that motivate Stephen Gould (1980) and colleagues to take a similar stance: as an answer to vulgar sociobiology (i.e., identifiable classes of genes directly cause identifiable classes of cultural behavior). The central message of memetics is that human beings can still be purely Darwinian creatures and yet possess a significant measure of independence from their selfish genes and from the blind processes of natural selection that ruthlessly govern biological evolution. (pp. 242-243)

He then proposes cultural epidemiology and the theory of modularity of mind as a third way:

But sociobiology is not the only Darwinian alternative to memetics. The multimodular mind, too, allows for obvious human creativity and much free play in thought. Unlike memetic hand waving, it does so by attempting to actually specify the cognitive tools available and the recurrent rules of their use in building cultures. (p. 243)

My argument is similar with regard to dual inheritance theory and evolutionary psychology, which tends to continue the above described dichotomy, but I will draw attention on the theory of cultural attraction rather than on the modularity of mind hypothesis. 
present and future, live. On the other hand, studies of transmitted culture tend to downplay the role of the constructive processes that produce the output.

An important fact that is concealed by the evoked/transmitted dichotomy is that the constructive processes themselves are not limited to evolved mental mechanisms. The constructive cognitive processes can evolve as a result of cultural transmission. First, mental processes evolve as a consequence of the feedback action of the distribution of cultural items. Enculturation is a particular feedback consequences of cultural phenomena since culture plays a role in mental development. People are not only learning new things, they are also learning to learn, as scientists in education like to say. Thus, enculturation refers to more psychological phenomena than the incremental acquisition of transmitted, cultural, beliefs and values. Enculturation and learning in general, have consequences on the generative mechanisms sustaining cultural evolution.

Second, the feedback actions of cultural phenomena change not only themental processes, but also the non-psychological environment that distributes cultural items. For instance, the availability of technical devices and other artifacts sometimes enables specific actions and thoughts. Mechanisms of distribution can involve mental and non-mental processes. This is the case with most institutions, which can include infrastructures and other material means (e.g., coercive means) as well as memorized procedures (Heintz,2007a).

Rather than assuming which processes produce cultural phenomena (imitation in dual inheritance theory or evocation in evolutionary psychology), cultural epidemiology prompts to describe these processes and thus enables going beyond the evoked/transmitted dichotomy. Social cognitive causal chains are, indeed, much more complex than simple reactions on some external and independent environment, and more complex than simple transmission chains. Historiographers are well aware of the numerous contingent and contextual causes that determine the course of history. I will now argue that such causes can be described within the 
framework of cultural epidemiology.

\section{Contextual causes in the production of cultural phenomena}

By a careful analysis of the distribution of cultural items and other environmental input to cognitive mechanisms, and a description of the cognitive mechanisms that occur at a time and place, one can specify which are the cognitive processes that most probably occur, and thus which representations occur more often and eventually stabilize so as to constitute cultural phenomena. Careful analyses of environmental stimuli (including cultural items) are already included in the historiographers' agenda. The analysis of the cognitive mechanisms that occur at a time and place, however, may require the aid of cognitive psychology. Cultural epidemiologists have been using and developing hypotheses about the structure of the mind that rely on methods from evolutionary psychology. On the basis of such psychological hypotheses, they have been able to specify which are the cognitive mechanisms that have had a significant role in the formation of this or that cultural phenomena (esp. religious beliefs, as in Boyer 2001). Yet, constraints coming from universal properties of the mind are but one factor that can stabilize representations in a population. Ecological factors and psychological factors issued from learning and enculturation do play an important role. As these factors may change over time, their dynamics can also account historical cultural changes.

Here are examples of contextual historical factors, which induced or permitted the recurrence of types of events in social cognitive causal chains:

Material means of communication: social interactions and communication are key events out of which cultures evolve. Social interactions happen when the input of some agent's mental processes is made of the output of some other agent's mental processes; this output is a change in the external environment that is itself constrained by this 
environment. For instance, a book can be produced at low cost only when the environment provides affordances for printing. Means of communication have been shown to have an important impact on cultural production. They eventually have great consequences on which cognitive processes get implemented (see, e.g., Goody 1977; Donald 1991).

Social constraints on the flow of information: preexisting distributions of representations can regulate who can talk to whom and about what. For instance, access to people with political power is often restricted to a small minority of the governed population. The use of the media for distributing one's idea is also regulated. Eventually, the flow of information across the population can be highly regulated by existing institutions. In particular, there can be local systems that assess the trustworthiness of sources of information and partly determine whether these sources can access to the attention of some audience - the differential prestige of scientific journals and search-engine mediated access to Web documents (Heintz, 2006).

Access to resources: more generally, access to resources, symbolic or other, is historically contingent, and determines which social cognitive causal chains there can be. This important Marxist point may be overlooked by studies of cultural evolution based on a definition of culture restricted to information acquired from others through social transmission (teaching, imitation, ...).

Enculturation: determines further actions: the historical context has someimpact on psychological factors, since it governs enculturation. Max Weber's study on protestant ethic is a case in point: it shows how religious complex and abstract ideas about 
afterlife can have effects on personality formation, and then on behavior. From a distribution of theological ideas, there evolves a distribution of ideas about oneself (e.g. as being chosen'), which partly determine economic decisions.

The first reason why cultural evolution is contingent upon historical factors is its cumulative aspect. For instance, it is only if I already know how to make a good kayak that I can improve it by using, e.g., some new sewing techniques. The examples above show that historical contingency is involved in several ways other than the ones due to the accumulation of cultural knowledge: significant factors in cultural evolution can include the existing artifacts, social organization and inter-relations of apparently independent beliefs. Rather than "cumulation", Wimsatt \& Griesemer (2007) talk about "scaffolding". They give several examples where complex cultural features arise from several pre-existing cultural phenomena. Their analysis of the history of Sears' Kit Houses, for instance, shows the rich set of factors that lead to the spread of those houses in the US from the 1890's to the 1930's. The Sears company advertised houses through catalogues and sold houses were sent in pieces by train. The factors of the success of the company, and thus of its cultural impact, include the railway infrastructure and low postal rate, the availability of cheap paper, and the fact that most Americans in the countryside did not have ready means to travel to retail stores in urban centers.

Thus, mail order emerged as means of extending the reach of department stores beyond the "neighborhood" defined by the travel distances of consumers, but it also leveraged a national expansion of successful retail stores. Both extensions took place through the catalog, scaffolded by the various institutional, technological and organizational innovations of society and government mentioned above. The Sears catalog became an icon of American popular culture. (Wimsatt \& Griesemer 2007, p. 239) 
How can we deal with this multiplicity of factors and their historicity? The best way is to come back to the events as they historically took place, and, I sustain, describe the social cognitive causal chains as they occurred. Of most interest to cultural historians, are the social cognitive causal chains that are representatives of recurrent types. These constitute mechanisms of distribution of cultural representations.

\section{Contextual factors of attraction}

Sperber (1996) talks about cultural attractors as positions in the space of possible "cultural items". In this space, two items are close to each other when they resemble each other, so a cultural phenomenon is constituted by the existence of many items close to each other in this space of possible items, and that are distributed in the population and its habitat, and through time. An attractor is "an abstract statistical construct" (p. 112). The notion ofattractor is not intended as an explanatory one, but as enabling the description of cultural phenomena that are constituted by the regular production of resembling cultural items. The regularities that are described with cultural attractors are such that the produced cultural items are statistically gathered around one ideal-type variant, which is then called the attractor. In the case of social transmission, social cognitive causal chains are made of repeated transmissions, where a first item leads to the production of a second item that resembles the first (e.g. a causal chain where a mental representation is reproduced in someone else's head). Such chains of repeated transmissions lead to the stable distribution of resembling representations and constitute cultural phenomena. Sperber argues that in most cases the social cognitive causal chains of cultural transmissions are such that there is a higher probability that the produced cultural items resemble the cultural attractor more than its antecedent variant in the cognitive causal chain, and a lesser probability that the produced variant resembles less the cultural attractor. 
The result is that, in the space of possible items, cultural items gather around cultural attractors: new items tend to resemble the cultural attractor as muchas they tend to resemble the antecedent variant in the transmission chain. The production of cultural items is such that they tend to resemble some cultural attractor as much as they tend to resemble the antecedent variant in the transmission chain.

Sperber (1996, chap. 5) argues that the notion of cultural attractor is a useful notion to describe cultural phenomena because there is no high fidelity in transmission and reproduction of cultural items. Even though there is a lack of fidelity at the level of cultural transmission (see also Sperber 2000), there is nonetheless stability at the population level. "Resemblance among cultural items is to be explained to some important extend by the fact that transformation tend to be biased in the direction of attractor position in thespace of possibilities" (Sperber 1996, p. 108). The social cognitive causal chains constitutive of social transmission often take the form of cognitive mechanisms that reliably produce an output that resemble the cultural attractor in spite of some variations in the input. For instance a tale can be memorized and recounted in the same way independently of the pitch of theinitial narrator, but also, and more importantly, independently of the specific words she used, and even with a relative independence of some of the events initially recounted. The causes of stability are therefore to be found in the constructive processes at work in social cognitive causal chains, such as the specifics of human memory and the reliance on evolved cognitive abilities. Cultural stability results from causal factors of attraction, which have for consequence a gathering of cultural items around cultural attractors.

There are multiple factors of attraction, and these factors are local andhistorical as well as universal (more precisely, derived from universal properties of the cognitive apparatus). Epidemiological studies of religious beliefs(Boyer 2001; Atran 2002) have focused on human universal psychological properties as factors of attraction. However, the 
position of attractors always depends on both properties of universal aspects of human psychology and of the shared context, local beliefs, development of local psychological properties, etc. As Sperber says "the factors that make for a good form [i.e.a form seen as being without either missing or superfluous parts, easier to remember, and more attractive] may be rooted in part in universal human psychology and in part in a local cultural context" (Sperber 1996, p. 108). Cultural phenomena can indeed act as ecological or psychological factors of attraction. First, properties of local material culture such as the alreadymentioned material means of communication can foster and constrain further cultural production. For instance, a type of musical instrument makes some tune easier to play and more pleasant to listen to because of its shape and specific sounds. ${ }^{5}$ Second, psychological factors are not always anchored directly in universal psychology. The local cultural context can determine psychological development in such a way that the ensuing psychological properties act as factors of attraction. For instance, the ability to play chess or to use an abacus influence human behavior on a cultural scale; these abilities also create a demand for material objectschess game or abacus in our case - and can have consequences on social organization - chess club or the organization of the market place and the form of economic exchange. More controversially, the specificity of the language spoken has some consequences on thinking (cf. the literature on the Sapir-Whorf hypothesis).

Here is a further illustration of the situational dependency of the position of cultural attractors. Sperber's example of a form of a tale as a cultural attractor is as follows: suppose that an incompetent teller has the hunters extract Little Red Riding Hood from the Big Bad Wolf's belly, but forgets the grandmother

\footnotetext{
${ }^{5}$ Their exist two types of bassoon, the Buffet bassoon and the Heckel bassoon, which require different fingerings for many notes and have distinctive sounds. Each type of bassoon seems to have a repertoire for which it is more adequate: the Heckel bassoon is more widely used, but the Buffet basso, which originated in France, is favored for playing music composed by Frenchmen. So it seems that the specificities of instruments have consequences on the music that is being composed and vice-versa.
} 
[...] hearers whose knowledge of the story derives from this defective version are likely to consciously or unconsciously correct the story when they retell it, and, in their narrative, to bring the grandmother back to life too. In the logical space of possible version of a tale, some versions have a better form: that is, a form seen as being without either missing or superfluous parts, easier to remember and more attractive (Sperber 1996, p. 108).

Why is the defective version of a bad form? Sperber does not tell at this point, leaving it to the intuition of the reader that the normal form is more attractive than the defective. A hypothesis, however, is that it is understood that the hunters are benevolent, since they are acting against the bad wolf. But benevolent people cannot so easily forget about the wellbeing ofa grandmother - this is, at least, what our naive psychology leads us to expect. Of course, cultural information also plays a role in the fact that we want to satisfy this expectation: the tale is intended for children for whom maximal relevance (Sperber \& Wilson 1986) may be attained when explaining how difficult situations can be sorted out (one just needs some benevolent hunters). Imagine however that the tale was to be told to teenagers among whom poking fun of grandmothers is highly appreciated. Telling a tale thatgoes against the expected behaviour would increase the relevance of the story: it would raise the question 'why did the hunters leave the grandmother in the wolf's belly?', opening up inferences such as 'leaving grandmothers in wolves' bellies is more benevolent than taking them out', 'we are better off when grandmothers remain in wolves' bellies' and so on. In both cases, both evolved cognitive abilities (I mentioned the working of naïve psychology in producing expectations about the hunters' behaviour) and cultural background information play a role as factors of attraction towards a specific form of the tale. In this example, the existence of a cultural attractor results 
from psychological factors of attraction. But these psychological factors arethemselves changing, depending on age-related expectations and interests: benevolence and problem solving in the case of young children and the undermining of moral norms of respect due to elderly people in the case of contemporary European teenagers. Of course, one can also note the dependence of the cultural attractor on kinship system or other factors, which can always be situated on a continuous scale from universal to local and contextual.

Cultural historical research mainly consists in specifying which factors gave rise to cultural phenomena. These factors may be multiple and historically contingent in a way that is not always recognized by current evolutionary theories of culture. For instance, Richerson \& Boyd (2005, p. 31-35) illustrate the power of cultural transmission in the face of variations in institutional and social environment by pointing out that post-Soviet countries have kept or recovered their own regional culture in spite of Soviet's actions against these local cultural traits. Indeed, transmissions of national values and ideas have played a great role in the formation of post-Soviet countries, but other factors come into play. In particular, the structure of the incentives should not to be ignored: what is to gain by adopting traditionalvalues? In the repertoire of traditions, why choose this one rather than the other one? In the Republic of Moldova - one of the post-Soviet countries - many people regret the fall of the Soviet era. The communist party has known a large success in recent years. Also, in a referendum in 1994, the people massively voted against the unification with Romania, with which they share most of their past and traditions. These events occurred in spite of the fact that around $72 \%$ of the population is Romanian. Discussions about what should be the national language (Romanian or Romanian renamed 'Moldovan', whether Russian should have a special status) show that past traditions are differentially promoted in the Republic of Moldova and that political and local interests have important effects. In the village where I stayed (10/04-01/05), on the bank of the Dniester, it clearly appeared that job prospects, opportunities to gain a little more 
money, were thought to be in Russia - West Europe was still thought as too inaccessible. There is a parallel between the selection of traditions that are maintained and theselection of features of the tale in the above example: what constitutes agood form, with a potential to stabilize, is contingent on current interests.

Does recognizing the multiplicity of factors directing cultural change makethe attempt to develop and use cultural evolutionary theory in history hopeless? No: complex processes and historical contingency have their place in a theory about the distribution of cultural items in a community and its habitat - in an evolutionary theory of culture that is still in the making. This implies, however, that understanding the multiplicity of factors and mechanisms of evolution should strongly rely on historiography as an important source of data. In spite of the multiple contingent factors that intervene in fixing the position of cultural attractors, there is nonetheless regularity in the cognitive causal chains producing items on a cultural scale. In order to account for this regularity, Boyer (1998) talks about "cognitive tracks". Cognitive tracks are cognitive causal chains that are more probable to occur than others, given a range of input. Their higher probability of occurrence is due to the fact that there are, already in place, cognitive mechanisms that are triggered by cultural input, with the result that sets of input generate similar sets of output. In his article, Boyer emphasizes the role of intuitiveontologies as forming the cognitive mechanisms that shape cognitive tracks and constitute factors of attraction. I have, on my part, emphasized that such cognitive mechanisms can also be the product of history: they can result from enculturation or be implemented through preexisting distribution of representations and their effect on the social organization of cognition (social management of the flow of information, social distribution of cognitive tasks). My claim, therefore, is that explanations in cultural historiography can take the form of specifying which cognitive mechanisms are in place; this in turn can explain which are the cognitive tracks likely to be taken given the input (e.g. the structure of incentives as causally implicated in 
beliefs about expected utilities) and also which input is more likely to be producedin social interactions. Boyer (1998) notices that when intuitive ontologies are not more or less directly relied upon, material and institutional support must be implicated in the production and distribution of items on a cultural scale. To this analysis, I add that the material and institutional support can also take the form of cognitive mechanisms upon which the production and distribution of cultural items rely. In other words, cognitive explanation spans larger than cognitive psychology, as has been shown by students ofdistributed cognition (Hutchins 1995). Cognitive mechanisms can be realized outside of the boundaries of the skull and so cognitive tracks can often cross-cut brains and environment.

\section{Conclusion}

Factors of attraction come from the properties of the cognitive mechanisms inplace (i.e. present in a given population and its habitat at a given time). Recognizing that cognitive mechanisms can change over time (especially because of enculturation and distributed cognition), is to give to cognitive studies of cultural evolution a new historical dimensins: factors of attraction themselves can change over time. The historicity of these factors tends to be ignored in accounts of cultural evolution of both evolutionary psychology and dual inheritance theory. Cultural epidemiologists also have not yet given full attention to the processes through which factors of attraction change. They have mostly focused on unchanging psychological factors. Yet, one aspect with which cultural epidemiology makes a difference with competing evolutionary theories of culture, is its ability to integrate and develop theories about multiple and changing cognitive mechanisms at work in the distribution of cultural items.

I hope that the arguments I have developed in this paper will appear tobe more than hand waving towards historians: when advocating the use of cultural epidemiology in cultural 
history, I have spelled out the advantages of the approach. Cultural epidemiology aims at describing the social cognitive causal chains out of which cultural items are being produced and distributed, it aims at specifying the behavioral and cognitive bases of cultural phenomena and it provides the conceptual tools (Sperber, 2001) for such inquiries. Explanatory power is gained by providing the opportunity for historiographers to use theories in cognitive science. Theories about intuitive ontologies have been the main focus of studies in cultural epidemiology, although a cognitive theory of communication (relevance theory of communication, see Sperber \& Wilson 1986) has always been, so to say, in the background (especially as an alternative to theories of cultural transmission that completely relyon 'imitation' as an ability for culture). In this paper, I have argued thatstudies of enculturation, and studies of situated and distributed cognition can also integrate and benefit studies in cultural epidemiology. Integrating such studies in cultural epidemiology should enable the cognitive study of what Wimsatt \& Griesemer (2007) have called "scaffolding" and "generative entrenchment" - the fact that the historical context constrain and makes possible the generation of new cultural items - in cultural evolution; it would provide some important bases for the development of cognitive cultural history, enriching our understanding of the cognitive mechanisms that distribute cultural item.

\section{References}

Akerlof, G. A.(1970). The market for 'lemons': Quality uncertainty and the market mechanism. Quarterly Journal of Economics 84 (3): 488-500.

Atran, S. (1990). Cognitive foundations of natural history: Towards an anthropology of science. Cambridge, UK: Cambridge University Press.

Atran, S.(2001). The trouble with memes. Human Nature 12 (4): 351-381. 
Atran, S. (2002). In gods we trust: The evolutionary landscape of religion. New York: Oxford University Press.

Barnes, B. (1977). Interests and the growth of knowledge. London/Boston: Routledge and Kegan Paul.

Boyer, P. (1998). Cognitive tracks of cultural inheritance: How evolved intuitive ontology governs cultural transmission. American Anthropologist 100 (4): 876-889.

-----. (2001). Religion explained: the evolutionary origins of religious thought. USA: Basic Books.

Chartier, R.(1990). Les origines culturelles de la R'evolution francaise. Paris: Seuil.

Clark, A. (1997). Being there: Putting mind, body and brain together again. USA: MIT Press.

Cosmides, L., \& Tooby, J.(1992). Cognitive adaptations for social exchange. In J. H. Barkow, L. Cosmides, \& J. Tooby (Eds.): The adapted mind: Evolutionary psychology and the generation of culture. New York: Oxford University Press, pp. 163-228

Donald, M.(1991). Origins of the modern mind: Three stages in the evolution of culture and cognition. Cambridge, MA: Harvard University Press.

Gilovich, T., D. Griffin \& D. Kahneman (Eds.) (2002). Heuristics and biases: The psychology of intuitive judgment. Cambridge, UK: Cambridge University Press.

Gooding, D. (1990). Experiment and the making of meaning: Human agency in scientific observation and experiment. Dordrecht, The Netherlands: Kluwer.

Goody, J. (1977). The domestication of the savage mind. Cambridge, UK: Cambridge University Press.

Gorman, M. (1992). Simulating science: Heuristics, mental models and technoscientific thinking. New Haven, Conn./London: Indiana University Press.

Heintz, C. (2006). Web search engines and distributed assessment systems. Pragmatics \& Cognition 14 (2): 387-409. 
----. (2007a). Institutions as mechanisms of cultural evolution: Prospects of the epidemiological approach. Biological Theory 2 (3): $244-249$.

-----. (2007b). Scientific cognition and cultural evolution: Theoretical tools for integrating social and cognitive studies of science. Unpublished doctoral dissertation, Ecole des Hautes Etudes en Sciences Sociales, Paris. Available at http://christophe.heintz.free.fr/thesis.

Hutchins, E. (1995). Cognition in the wild. Cambridge, MA: The MIT Press (Bradford Books). Martens, B. (2004). The cognitive mechanics of economic development and institutional change. New York: Routledge.

Martin, L. (2005). Introduction: Imagistic traditions in the Graeco-Roman world. Historical Reflections/Réflexions Historiques, 31 (2), 297-307.

Nersessian, N. J. (1984). Faraday to Einstein: Constructing meaning in scientific theories. Dordrecht: Kluwer.

-----. (1992). How do scientists think? capturing the dynamics of conceptual change in science. In R. N. Giere (Ed.). Cognitive models of science. Minneapolis, MN: University of Minnesota Press. pp. 3-45

-----. (1995). Opening the black box: Cognitive science and history of science. Osiris (2nd Series) 10: 194-211.

-----. (2002). Maxwell and "the method of physical analogy": Model-based reasoning, generic abstraction, and conceptual change. In D. Malament (Ed.). Essays in the history and philosophy of science and mathematics. Lasalle, Il: Open Court. pp. 129-166

Netz, R. (1999). The shaping of deduction in greek mathematics: A study in cognitive history. Cambridge, UK: Cambridge University Press.

North, D. C. (2005). Understanding the process of economic change. Princeton, New Jersey: Princeton University Press. 
Ory, P. (2004). L'histoire culturelle. Paris: PUF, (coll. Que sais-je ?).

Potts, J. D. (2000). The new evolutionary microeconomics: Complexity, competence and adaptive behaviour. Cheltenham, UK: Edward Elgar.

Richerson, P. J. \& R. Boyd (2005). Not by genes alone: How culture transformed human evolution. Chicago, IL: The University of Chicago Press.

Salmon, C. A. \& T. K. Shackelford (Eds.) (2007). Family relationships: An evolutionary perspective. New York: Oxford University Press.

Sperber, D. (1996). Explaining culture: A naturalistic approach. Oxford: Blackwell.

-----. (2000). An objection to the memetic approach to culture. In R. Aunger (Ed.).

Darwinizing culture: The status of memetics as a science. Oxford, UK: Oxford University Press. pp. 163-173.

-----. (2001). Conceptual tools for a natural science of society and culture. Proceedings of the British Academy 111: 297-317.

-----. (2006). Why a deep understanding of cultural evolution is incompatible with shallow psychology. In N. Enfield \& S. Levinson (Eds.). Roots of human sociality: Culture, cognition and interaction.Oxford: Berg. pp. 431-449

Sperber, D. \& D. Wilson (1986). Relevance: Communication and cognition. Cambridge, MA, USA: Harvard University Press.

Tooby, J. \& L. Cosmides (1992). The psychological foundations of culture. In J. H. Barkow, L. Cosmides, \& J. Tooby (Eds.). The adapted mind: Evolutionary psychology and the generation of culture. New York: Oxford University Press. pp. 19-136.

Tweney, R. (1985). Faraday's discovery of induction: A cognitive approach. In D. Gooding \& F. A. J. L. James (Eds.). Faraday rediscovered: Essays on the live and work of Michael Faraday. New York: Stockton Press. pp. 189-210.

-----. (1991). Faraday's notebooks: The active organization of creative science.Physics 
Education 26: 301-306.

Vial, T. (2005). Can memory fill in gapes of memory? Applications of the cognitive science of religion to the history of religion. Historical Reflections/ Réflexions Historique 31 (2), $283-295$.

Whitehouse, H. (2004). Modes of religiosity: A cognitive theory of religious transmission. Walnut Creek, CA: AltaMira Press.

-----. (2005). Cognitive historiography: when science meets art. Historical Reflections/ Réflexions Historiques 31 (2), 307-318.

Wimsatt, W. C. \& J. R. Griesemer (2007). Reproducing entrenchments to scaffold culture: The central role of development in cultural evolution. In R. Sansom \& R. Brandon (Eds.), Integrating evolution and development: From theory to practice. Cambridge, MA: MIT Press. pp. 227-323.

Witt, U. (2003). The evolving economy: Essays on the evolutionary approach to economics. Cheltenham, UK: Edward Elgar. 